\title{
La Noviolencia en los Nasa, del norte del Cauca: relaciones entre la teoría y la experiencia específica
}

\author{
Daniel Ricardo Martínez Bernal \\ Universidad de Granada, Granada, España. \\ Email: drmart@correo.ugr.es
}

\begin{abstract}
Resumen: ${ }^{1}$ Las resistencias indígenas del Cauca constituyen algunos de los principales caminos y alternativas a los ciclos de violencia vividos en Colombia. A través del método histórico comparativo, la acción participante y las entrevistas en profundidad; se recogieron datos que permitieron conocer las concepciones y significaciones propias de las comunidades indígenas frente al concepto de Noviolencia. La comparación teórico-práctica, las relaciones (similitudes y divergencias) entre los datos encontrados en el concepto de Noviolencia y las aportaciones teóricodoctrinales de la resistencia Noviolenta, permitieron analizar la Noviolencia entendida por las comunidades indígena Nasa en el departamento del Cauca, Colombia, a través de hechos y experiencias. Se parte de la hipótesis de que existen unas condiciones político-practicas, que llegan a constituir un ejemplo de dirimir los conflictos y hacer política de manera no armada, civil y no cruenta, sobre todo en un contexto como el colombiano. Son experiencias representativas donde hay luchas de tipo "genéricas”, pero también perdurables o "especificas", como producto de la evolución de un pensamiento histórico y resistencia.

Palabras clave: Noviolencia, Pueblo Nasa, Resistencia Nasa, Noviolencia especifica.
\end{abstract}

\section{Nonviolence in the Nasa people, from northern Cauca: relation between theory and specific experience}

\begin{abstract}
Indigenous resistances in the Cauca department constitute some of the main alternatives to the violence cycles experienced in Colombia. Through historical comparison methodology, participatory action and in-depth interviews, data was collected, which allowed knowledge of the indigenous communities' own ideas and meanings around the concept of nonviolence. A practical-theoretical comparison, the relations (similar and divergent characteristics) between the data on the communities' concept of nonviolence and the theoretical and doctrinal statements of non-violent resistance, allowed an analysis, based on practices and experiences, of non-violence as understood by the indigenous communities of the Cauca department in Colombia. The research is based on the hypothesis that the studied communities have specific political and practical conditions which constitute them in an example of conflict resolution and political action through un-armed, civil, un-bloody means; especially for the Colombian context. They have experiences showing "generic", but also lasting, struggles, and "specific struggles", products of the evolution of a historical resistance thought.
\end{abstract}

Keywords: Nonviolence, Nasa people, Nasa resistance, Specific nonviolence. 


\section{A não-violênciados Nasa do norte do Cauca: relações entre a teoria e a experiência específica}

Resumo:As resistências indígenas do Cauca constituem alguns dos principais caminhos e alternativas para os ciclos de violência vividas na Colômbia. Através do método histórico comparativo, aação participante e as entrevistas em profundidade se colheram dados que permitiram identificar as concepções e significações próprias das comunidades indígenas sobre o conceito de não-violência. A comparação teórico-prática, as relações (semelhanças e diferenças) entre os dados encontrados no conceito de não-violência e as contribuições teóricas e doutrinárias de resistência não-violenta, permitiram analisar a Não-Violência compreendida pelas comunidades indígenas da Nasa, no departamento de Cauca, Colômbia através de eventos e experiências. Parte-se do pressuposto de que existem algumas condições políticas e práticas que vêm a constituir um exemplo de resolução de conflitos e de fazer política de maneira desarmada, civil e não-cruenta, especialmente num contexto como o colombiano. São experiências representativas em que existem lutas de tipo “genéricas”, mas também perduráveis, ou “específicas”, como produto da evolução de um pensamento histórico e resistência.

Palavras-chave: Não-violência, Povo Nasa, Resistência Nasa, Não violência especifica.

$* * *$

\section{Introducción}

Este articulo abordará el concepto de Noviolencia, que ha sido analizado en la investigación de tesis doctoral titulada: "Caminando hacia la Satyagraha. Comunidad, lucha y Kweet Fxindxi en los Nasa (1972-2015)” (Martínez 2016), sobre la resistencia y la comunidad $\mathrm{Nasa}^{2}$ en el norte del departamento del Cauca, Colombia, desde una óptica de los estudios para la paz y la Noviolencia. En estas líneas, se pretende mostrar la relación existente entre lo que conciben las comunidades indígenas Nasa como la Noviolencia, y la teoría - principalmente la gandhiana-.

El caso de las comunidades indígenas Nasa del norte del Cauca, o como así mismos se hacen llamar "procesos de resistencia indígena comunitaria”3, tiene sus antecedentes más claros en 1971 con el Consejo Regional Indígena del Cauca (CRIC) que nace en seno de la Asociación Nacional de Usuarios Campesinos (ANUC) en 1967, creada por Carlos Lleras Restrepo, -Presidente Colombiano-. La Asociación de Usuarios campesinos tuvo su auge de 1966 hasta 1970, e hizo parte de uno de los tantos intentos de reforma agraria en Colombia. De esta forma, para 1971 con el fin y el propósito de buscar reivindicaciones y respuestas a las necesidades propias de los indígenas, como pueblo y como comunidad, se crea esta primer consejo indígena impulsada por los resguardos de Toribío, Tacueyó, San Francisco, Jambaló, Guambía y Pitayó, con la participación de diferentes líderes tanto indígenas como no indígenas. Esto hecho permitió el fortalecimiento de entidades como los cabildos y planteó los puntos de lucha, principios y valores de la resistencia como lo es la Unidad, la Tierra, la Cultura y la Autonomía. Bajo estos principios se empiezan a construir dife- 
rentes alternativas a problemáticas tan profundas que se encontraban en el territorio.

En 1980 gracias al impulso de diferentes iniciativas locales, como la llevada a cabo por el sacerdote Nasa Álvaro Ulcué Chocué nacen planes, programas y proyectos como el Proyecto Nasa, que tenía como propósito fundamental consolidar a las comunidades de Toribío, Tacueyó y San Francisco $^{4}$. Esta sería la primera iniciativa que continuaría con los principios y fortalezas planteados por el CRIC, pero de allí germinaran otras propuestas como el Proyecto Global en Jambaló, o los procesos de la María y Caldonó.

La Asociación de Cabildos del norte del Cauca (ACIN) nace en 1993, aprovechando el decreto 1088 de 1993 que permite la asociación de cabildos. La ACIN se constituye en un ejemplo claro de organización Noviolenta frente a la guerra, y como referente de unión de los diferentes proyectos, que buscan generar mejores condiciones de vida, responder frente a las necesidades básicas insatisfechas y de igual modo frente a la construcción de una mayor unidad territorial o vertebración de estos territorios, donde se emprende una lucha por la dignidad generalizada de las comunidades indígenas del Cauca.

Por su parte la Noviolencia, esun concepto que ha sido estudiado y conceptualizado por varios autores, en donde por ejemplo para Gandhi es definida a partir del término Ahimsa que expresaba la connotación de no matar, no causar daño o sufrimiento. Para Martin Luther King Jr, significaba la fuerza de amar. Lanza de Vasco, por su parte la definió como "la manera activa de combatir el mal”; León Tolstoy, la denominó como la fuerza “más subversiva de los fusiles”, y por último Aldo Capitani se refería a ella como una forma de "rebeldía permanente" y a su vez como "el gobierno de todos" (López 2004:308).

López (2004) identifica como uno de los principios básicos de la Noviolencia el no matar, que se entiende como principio y exigencia dentro de la Noviolencia. Se busca la exaltación de la condición humana, lo cual va en congruencia con el respeto a la vida; se parte del abandono expreso de la violencia, frente al hombre y a la naturaleza en sí, donde no se trata sólo de no matar, sino de intentar no producir daño, dolor o sufrimiento a ninguna criatura. Este principio parte de dos presupuestos, el primero, que todos los seres son responsables y debe respetarse su derecho a decidir sobre su vida, y segundo que él no matar, debe ser visto no sólo como un principio sino a su vez como un derecho. La Noviolencia es una doctrina ético-política, bajo principios que se basan en el respeto de la vida humana, en la búsqueda de la verdad -ética y epistemológica- parte de una ética dialógica, que pretende ser una forma creativa y alternativa de pensamiento y acción político social.

Teniendo en cuenta estos dos elementos, se evidenciaran las relaciones entre lo que entienden las comunidades indígenas Nasa del norte del Cauca, por Noviolencia y lo que entendía Gandhi a la hora de pensar en 
su lucha Satyagraha y sus principios, al igual que, los posteriores conceptos como el de Noviolencia pragmática o especifica que abordaran otros investigadores posteriores.

Por esta razón y para efectos metodológicos este artículo estará dividido tres bloques: El primer bloque, son algunos aspectos teóricos, que son necesarios tener en cuenta a la hora de abordar el concepto y el estudio de la Noviolencia como acción y doctrina filosófica. El segundo bloque, se presentaran algunos resultados relevantes del trabajo de campo, en el Cauca, Colombia, donde se toma el caso concreto del concepto y la cosmovisión que tienen las comunidades Nasa de Noviolencia.

Y finalmente tercero y como último bloque, se hará una comparativa, entre los presupuestos teóricos presentados en la primera parte, y los resultados expuestos en la segunda. De esa manera, se podrán evidenciar, algunas similitudes o relaciones, al igual que especificidades.

\section{Aspectos teóricos: el concepto de noviolencia}

\section{La mal llamada resistencia pasiva ¿cómo se resiste?}

Aunque las expresiones de desobediencia, desacuerdo, desacato, resistencia están presentes a lo largo de toda la historia de la humanidad, es a finales del siglo XVIII con acontecimientos como la Revolución Francesa o de procesos de Independencia de EE.UU., cuando las ideas de resistencia y revolución toman fuerza.

De esta manera las manifestaciones de resistencia se proliferan no sólo hechos violentos como el de la Bastilla, sino que a lo largo de los siguientes siglos van a convivir otras manifestaciones como el Cartismo, el Carbonismo, las sufragistas, el Luddismo, entre otras que son formas de resistencia, que no cuentan con el recurso de las armas.

Partiendo de las ideas de Randle (1998) a raíz del estudio de Tilly, se puede ver que en términos generales las formas de resistencia de estos momentos eran principalmente pacíficas ${ }^{5}$. Sin embargo hay dos cuestiones que las llevan a tender al uso de las armas: primero, que parte de las ideas revolucionarias -principalmente de las corrientes marxistas y anarquistas-, que se incrustará tan profundamente en los idearios revolucionarios, en donde los medios no armados pasarán a ser considerados como ineficientes, inoficiosos y, sobre todo, inocuos. Es tan generalizada esta tendencia que los movimientos y resistencias pacifistas serán vistas y denominadas como posturas moderadas o, como fue llamada por muchos pensadores del momento, utópicas.

La segunda cuestión que influyó en la proliferación de las luchas armadas y del contenido de la violencia en estas esferas, fue la misma institucionalidad o autoridad, que se dio cuenta de que la represión de los 
gobiernos en manifestaciones, se llevaba a cabo bajo la convicción de que la defensa y respuesta por parte de los manifestantes sería igualmente agresiva o violenta. Así los mismos gobiernos eran incitadores de una escalada de violencia en la que, finalmente, los mayores beneficiarios serían las fuerzas armadas y profesionalizadas. Esto dejaba detrás del telón la idea de que cualquier manifestación o resistencia sin el uso de las armas estaba abocada al fracaso.

En esa medida no es de extrañar que, poco a poco, se fuese dando una distinción alrededor del uso de lo que eran métodos armados y otros no armados. A los procesos que empezaron a desarrollarse por medios diferentes a las armas se les denominó en primer momento como resistencia pasiva. Para Randle (1998:49-50) el término concretamente aparece en el libro de Shelley (1819) "La máscara de la Anarquía”, donde a la resistencia sin el uso de las armas es igualmente despreciado y ridiculizado ${ }^{6}$. De esta forma la resistencia pasiva se convierte en uno de los conceptos más generalizados a lo largo del siglo XIX y XX.

De tal forma, conceptos como el de la Noviolencia ha sido malentendido también de esta manera -pasiva- sin embargo, no se pude negar que han sido un punto de partida en términos de acción política, y no uno de llegada.

Este punto de partida, como es la resistencia pasiva, se alimenta y se configura progresivamente con las ideas de de diversos autores, entre ellos de Thoreau. Generalmente se hace referencia a Thoreau por acuñar el concepto de Desobediencia civil, sin embargo, al momento de desarrollar sus ideas, y presentar su primer ensayo en 1848 y su posterior publicación en 1849, no se titulaba como lo conocemos hoy en día "Sobre el deber de la Desobediencia Civil", sino que se titulaba "Resistencia al Gobierno Civil”. Es solo hasta 1866, cuatro años después de su muerte, que se le da el título definitivo que conocemos ahora (Herranz1992:21). De esta manera aunque el fenómeno de desobedecer o de resistir frente al gobierno es más algo antiguo, son los postulados de Thoreau los que más han influenciado a las teorías y los pensadores de habla inglesa, porque además de referirse y partir de un caso como el norteamericano en el que se puede hablar de una resistencia contra un gobierno “civil”, también tiene en cuenta una visión pragmática y moral de la resistencia, por lo que ha sido estudiado por pensadores como Sharp que se centran en lo pragmático, hasta personalidades como Gandhi que sin perder de vista los métodos, le da mayor importancia a los valores.

El concepto de resistencia pasiva, se trasformará y empezará a tomar valor y relevancia a partir de Gandhi, quien reivindica su condición activa y valiente, y quien genera toda una teoría y un entramado que denominó Satyagraha.

Para diferenciar de la mal llamada resistencia pasiva y la Satyagraha, Gandhi distingue tres tipos o formas de Noviolencia. Primero, la Noviolencia 
del cobarde, que puede ser asociada como tal con la pasividad, y es cuando no hay confrontación, se huye, no se espera y se resiste, sino que renuncia a luchar. Segundo, la Noviolencia del débil, que es aquella que recurre a los métodos de lucha no armada por hechos o razones circunstanciales, son el preámbulo o la espera del uso de los recursos armados y la toma del poder. Y tercero, la Noviolencia del fuerte o Satyagraha (López 2006:154).

La Noviolencia se puede interpretar como "el deber y la acción por la justicia, respetando la vida y la integridad de los adversarios en esa lucha" (López 2004: 311). En este sentido, es necesario tener presente que la Noviolencia parte de la humanización de la política, la cual se traduce en una "lucha no armada y no cruenta contra las injusticias" (Ibídem)7.

\section{Tipologías y formas de entender la Noviolencia}

Dentro de la condición multifacética de la Noviolencia, al referiremos a su esfera políticaes necesario introducir el concepto de acción política noviolenta. "La Noviolencia significa renunciar al uso de la violencia pero no al uso de la política” (López 2004:342). La acción política noviolenta es cualquier acción con la intención de intervenir en el ámbito político de la sociedad -puede ser de tipo revolucionaria, para enfrentarse contra un enemigo militar, o para enfrentarse a una ley considerada injusta-, renunciando al uso de la violencia.

La acción política noviolenta trata la relación gobernar-obedecer. Se fundamenta en dos principios que se entienden como propiedades de esta relación. El primero es que la obediencia es necesariamente voluntaria. Es decir, que la obediencia de alguien frente a un gobierno no está per se asegurada sino que depende de su voluntad y juicio -constantemente cambiantes, o con posibilidad de ello-. Así, el gobierno no puede obtener obediencia, al menos no permanentemente, usando solamente la coerción. A partir de lo anterior podemos llegar al segundo principio: el consenso puede ser retirado. Bajo esta perspectiva puede entenderse el principio que fundamenta la desobediencia civil, la objeción de conciencia y la resistencia civil.

Es preciso aclarar que la acción política noviolenta, se fundamenta en, y principalmente significa, los métodos y las estrategias, los primeros se entienden como las herramientas, acciones o técnicas para intervenir sin el uso de la violencia de manera política, el mundo social. Por ello es importante ver los 198 según Gene Sharp quien clasifica estos métodos en tres categorías, a) persuasión y protesta, b) métodos de no-cooperación y no colaboración social y política y económica, c) intervención noviolenta (Sharp 1973). Las estrategias por su parte, hacen referencia al fin último, la meta o el propósito esencial de las acciones. Por tal razón, el fin político o la estrategia de la Noviolencia es el deslegitimar todo tipo de violencia, convertir al adversario -partiendo de la convicción de convencer en vez de vencery conquistar la voluntad del adversario - vista como la forma de obtener el poder-. 
Entre el mero uso de los medios o métodos para cualquier fin, y el uso de los métodos con fines específicos, nace una tipología de Noviolencia, o dos acepciones del concepto de Noviolencia que podemos encontrar en Pontara (1982). La primera acepción la llama Noviolencia pragmática ${ }^{8}$, en la que, a) nos referimos a un conjunto de métodos de lucha, b) caracterizados negativamente como exentos de violencia y c) cuyo empleo es de por sí compatible con cualquier doctrina o ideología por cuanto nada excluye que puedan ser empleados, por razones tácticas, por cualquier grupo con vistas a cualquier fin o por cualquier causa, sea justa o injusta.

La segunda acepción es la Noviolencia específica ${ }^{9}$ la cual se entiende como una doctrina que:

Propone un ordenamiento político fuertemente descentralizado, cuyas estructuras básicas están constituidas por consejos de ciudadanos organizados por fábrica, barrio, pueblo, etc., provistos de amplios poderes decisionales, fundados en el método democrático por lo que respecta a las cuestiones de política local, provistos de un poder efectivo sobre las decisiones que consideran a toda la comunidad. La doctrina noviolenta teoriza ampliamente la socialización de los grandes medios de producción, para los que auspicia la autogestión por parte de los trabajadores, pero deja en cambio abierta la cuestión acerca del grado que ha de estar planificada la economía en una sociedad tal (Pontara, 1982:1057).

Estas ideas se pueden aplicar a las comunidades indígenas, siguiendo el ejemplo más representativo que se ha estudiado desde la teoría noviolenta y es la que representa y ejemplifica la experiencia de Gandhi en la India.

Gandhi es el primero en formular y construir toda una teoría política sobre la resistencia. Sintetiza y descodifica toda una serie de, hechos, acciones, teorías y pensamientos tanto de Oriente como de Occidente y los transforma más que en una teoría, en una forma de vida, practicada por él y muchos de sus seguidores.

En un tema tan espinoso como es la política, en donde tradicionalmente la desvinculación de la moral en la labor del "príncipe” era señal de fuerza, poderío estabilidad, severidad, dureza, inclemencia; donde "el fin justifica los medios" (Maquiavelo 1999), y donde "la guerra es la continuación de la política por otros medios” (Clausewitz 2010), es normal que las ideas de Gandhi hayan dado un vuelco tan relevante y que la ética haya sido tan apreciable en el entramado de su discurso.

Gandhi a lo largo de toda su vida escribió gran cantidad de artículos y textos muy pequeños, que se ha ido recogiendo a largo de antologías y completos volúmenes ${ }^{10}$, que reflejan la riqueza y la complejidad de su pensamiento. Sin embargo, para poder abordar de una manera sistemática y organizada su pensamiento, algunos académicos como Pontara, han sabido 
sintetizar sus pensamientos en seis principios o doctrinas que fundamentan como el bien lo llama este "gandhismo”. La siguiente cita refleja muy bien esta idea:

De manera que, sólo mediante un trabajo de interpretación y sistematización de las variadas ideas filosóficas, metafísicas, religiosas, éticas, económicas y políticas contenidas en todos estos escritos, es posible intentar la reconstrucción de una doctrina ético-política, a la cual se le podría dar el nombre del "gandhismo". Pero no se trata de un término como el que se pueda referir a cualquier otro "ismo" pues Gandhi repudió siempre esto. Así los conceptos fundamentales de esta doctrina son seis: Satya, [verdad], Ahimsha, Sarvodaya [Bienestar de todos], Swaraj [autodeterminación, autogobierno], Satyagraha [lucha por la verdad] y Swadeshi [Autosuficiencia]. (Pontara 2004: 493) ${ }^{11}$

Estos conceptos son fundamentales al abordar el caso de la resistencia indígena del norte del Cauca, la medida se presenta la idea de descentralización política, de la redistribución del poder, a partir de la participación, la organización, la toma de decisiones y el ejercicio de un poder efectivo. Hace hincapié en la sociabilización de los medios de producción y de la idea de procesos de autogestión y autosuficiencia, en los que es la misma sociedad quien planifica, su economía, su política, y todos los aspectos de su vida diaria, según sus necesidades y contextos.

\section{Contextos en lo que se emprende un proceso de resistencias noviolenta ¿para qué se resiste?}

Partiendo de la tipología presentada por el Mario López (2001), ${ }^{12}$ los tres ejes de reivindicación y conflicto en los que se pueden situar los procesos de resistencia son: a) la lucha contra la dominación colonial, b) la lucha contra los regímenes autoritarios, dictatoriales y totalitarios y c) la reivindicación de derechos y libertades democráticas y ciudadanas, por la solidaridad internacional, por la ecología y en defensa de la naturaleza, por otro mundo posible ${ }^{13}$. Se pueden explicar con estos aspectos:

a) La lucha contra la dominación colonial: esta resistencia es una reivindicación y un conflicto que nace, con la presencia y dominio de los imperios, principalmente europeos. En este sentido el conflicto emerge más que por la presencia del “otro”- por el vínculo de dominio y opresión que se crea hacia los pueblos autóctonos o indígenas. Para deshacer estos vínculos de dominio, la lucha está acompañada de tanto combates armados como no armados.

De esta manera, para López (2013), existen varios ejemplos a lo largo de la historia ${ }^{14}$ en los que se evidencia una resistencia no armada frente a la dominación colonial, sin embargo en relación a las comunidades indígenas Nasa, el caso más representativo e importante que se puede encontrar en la lucha de independencia de la India, o lucha Satyagraha de Gandhi. El ejem- 
plo de esta experiencia en la India caracterizado por ser un proceso organizado de no-colaboración de masas, será el que marcará el futuro y las posibilidades de emancipación de la Noviolencia. Es dentro de este tipo y eje de resistencias en el que podemos clasificar a la resistencia llevada a cabo por las comunidades Nasa.

b) La lucha contra los regímenes autoritarios, dictatoriales y totalitarios: Al estudiar estas luchas, se puede ver que el paradigma predominado de la violencia en la historiografía, ha difuminado y silenciado el papel de la lucha noviolenta. El hecho de que este tipo de sistemas usen como principales métodos la represión y la restricción de las libertades, convierten a la resistencia armada en legitimador para dicha la represión, mientras que a la Noviolencia, la convierten en una alternativa real. En esta medida, los casos de luchas y resistencias sin el recurso de las armas, aunque han sido oscurecidos, han estado presentes y ha sido muy importantes y significativos a lo largo de la historia ${ }^{15}$.

Un claro ejemplo de estudios que han partido sus análisis desde este contexto lo encontramos en Sémelin (1993) y su texto, "Sin armas frente a Hitler. La resistencia civil en Europa, 1939-1943" quien brinda otra perspectiva de la historia de segunda Guerra Mundial, al igual que una definición de lo que desde sus presupuestos el podría definir como una resistencia civil.

c) La reivindicación de derechos y libertades democráticas y ciudadanas, por la solidaridad internacional, por la ecología y en defensa de la naturaleza, por otro mundo posible: los casos de resistencias que han hecho uso métodos de acción noviolenta, para la búsqueda y defensa de los derechos humanos, es muy amplio y se puede evidenciar tanto en los antiguos movimientos sociales del siglo XIX, como en los nuevos movimientos que han surgido a lo largo del siglo XX y XXI. Son muchas las manifestaciones y las formas en las que la Noviolencia ha sido una gran protagonista.

Para ejemplificar tanto las luchas contra totalitarismo y por los derechos y libertades, se puede hacer referencia a los análisis de Randle quien da relevancia a la teoría del Satyagraha de Gandhi, pero que también especifica que se trata de casos directamente relacionados con fines y sueños hacia y desde los conceptos de democracia occidental.

Finalmente, teniendo en cuenta esta tipología que ayuda a contextualizar conceptos como el de resistencia civil, desobediencia civil o resistencia noviolenta, y habiendo abordado los puntos de vista más generales desde los que se estudia la teoría y práctica de la Noviolencia, partiendo no sólo de acciones, formas o cómo se resiste, sino también sus valores, fines, y para qué se resiste -motivo de las reivindicaciones y del conflicto, es necesario abordar los resultados que se encontraron a la hora de preguntarles a las comunidades indígenas Nasa del norte del Cauca, por: ¿qué es la noviolencia para las comunidades? 


\section{Resultados del concepto y la cosmovisión Nasa de Noviolencia}

\section{Metodología}

Este apartado se sustenta en una serie de entrevistas, producto del trabajo de campo que se realizó entre los meses de abril y junio de 2014 principalmente en las ciudades de Popayán, Santander de Quilichao, departamento del Cauca, Colombia, y en Bogotá, Colombia, donde se encuentran el Consejo Regional Indígena del Cauca (CRIC), la Asociación de Cabildos Indígena del Norte del Cauca (ACIN) y la Organización Nacional de Indígenas del Cauca(ONIC), respectivamente. Las personas que se entrevistaron tienen un alto nivel de participación, implicación, y conocimiento del movimiento indígena al igual que reconocimiento dentro del mismo, por lo que se dividieron en tres perfiles, líderes, miembros de las organizaciones y académicos expertos en el tema, en donde se realizaron veintidós entrevistas por medio de las que se alcanzó la saturación teórica.

Las preguntas de la entrevista se desarrollaron en cinco ámbitos desde los que partió el guion semi-estructurado:

Conceptos cosmovisión, se indagó por conceptos que son tenidos en cuenta por las comunidades a partir de la revisión bibliográfica como: armonía, bienestar, autonomía, autosuficiencia, tierra, violencia, paz, unidad, verdad, poder, resistencia y Noviolencia. En el presente artículo nos centraremos únicamente en el concepto de Noviolencia.

Aspectos sociales, se preguntó, por la familia, las relaciones comunitarias Nasa, el papel de las mujeres, la minga y las relaciones económicas y de producción.

Historia, se consultó por la historia de los últimos diez años.

Aspectos políticos, se indagó concretamente sobre la Autoridad propia, entiéndase cabildo, y resguardo y su derecho propio; por el liderazgo; la toma de decisiones; la resolución de los conflictos, y la Guardia Indígena.

Procesos de resistencia comunitaria, se preguntó por los procesos de resistencia el CRIC y el ACIN como partes, luego como unidad, para finalmente preguntarles por la resistencia Noviolenta.

Una vez efectuadas las entrevistas se pasó a analizar los datos, buscando interpretar la realidad social -fenomenología-, y desde los datos obtenidos en las entrevistas -análisis discurso y/o contenido- y a través de la creación y comparación-contrastación de categorías -componentes de la Teoría Fundamentada- mediante el uso de software informático ATLAS.TI, se evidenciaron unos resultados y se compararon la resistencia Nasa y el gandhismo. 


\section{Resultados de la definición de Noviolencia de las entrevistas a las comunidades indígenas Nasa del norte del Cauca.}

De esta manera, teniendo claro que el foco de nuestra atención son los resultados encontrados al analizar el concepto de Noviolencia son:

1. La Noviolencia está asociada a su cosmovisión como armonía o equilibrio, al igual que conceptos como el de bienestar, o el de Kweet Fxindxi.

Este resultado aunque se encuentra de manera reiterada en varios entrevistados, la definición más clara a este respecto no la da una de las lideresas, al afirmar que la noviolencia: "es estar bien,es el Kweet Fxindxi, es el equilibrio y la armonía...es el respeto por la vida, es la relación con la naturaleza, es la manera como se media, es el dialogo y este aspecto es fundamental”.

2. La Noviolencia se entiende como la tolerancia, el diálogo, el respeto por el otro, su entendimiento. Es el dirimir los conflictos sin necesidad de la violencia.

Esta definición de noviolencia la expresan diversos líderes como miembros de la comunidad, siendo uno de los resultados más mencionados. El ejemplo más representativo de esta definición de noviolencia para los Nasa lo encontramos en la voz de dos líderes comunitarios en donde el primero de ellos afirma que: "la Noviolencia es resistir sin armas, desde una resistencia civil”. "Es hablar, dialogar con el enemigo, utilizar la lógica y la razón”. Otro líder concuerda y dice que "es la idea es dialogar sin llegar al uso de la fuerza y sin imponer al otro su postura". En este resultado es importante resaltar un matiz que hace uno de los miembros al afirmar que "la Noviolencia trata de explicar que la resolución de conflictos no se hace a través de las armas o el empleo de las distintas formas de violencia, sino con una actitud muy revolucionaria”, y que en esa medida es importante el legado del propio Gandhi quien quizá, para este miembro, "tampoco estuviese muy contento con el concepto de Noviolencia”.

\section{La Noviolencia se ve como un elemento equiparable, o como un fin o sueño que las comunidades indígenas quieren alcanzar.}

Este resultado aunque es comentado tanto por diferentes líderes como miembros, es especialmente explicitó en la definición de uno de estos líderes comunitarios quien afirma que: "si la violencia es un desequilibrio entre diferentes lógicas", entonces "la Noviolencia debe ser la forma de actuar de la comunidad indígena y uno de sus fines comunitarios, como es el aprender a resolver los conflictos sin recurrir a la violencia armada”. De esta manera la Noviolencia la equiparan e incorporan a los sueños de las comunidades.

4. La Noviolencia es pensarse como un actor dentro de una sociedad, el cual toma decisiones, obedece o no, decide qué tolerar, participa y construye. 
Este resultado al igual que los anteriores, aunque está presente en la opinión de varios entrevistados, es en la opinión de dos miembros donde queda mejor reflejada, el primero de estos miembros afirma que: "la Noviolencia se entiende como una cuestión de igualdad y de tolerancia, que se construye entre todos y que cuesta mucho trabajo y esfuerzo (...) la Noviolencia es tolerancia, pero determinando y dejando claro en todo momento qué es lo que se tolera”. El segundo miembro complementa diciendo "la Noviolencia es compartir, dialogar, reflexionar y ser solidarios. No eliminar al otro sino debatir sobre su pensamiento, es la lucha de la vida por la vida”.

\section{La Noviolencia es entendida estratégicamente como una forma o medio distinto de operar o de actuar, la cual trae consigo mejores resulta- dos.}

La afirmación que mejor sustenta este resultado lo encontramos en uno de sus líderes en donde para él, los Nasa decidieron avanzar hacia otros modelos de resistencia "porque se dieron cuenta de que la resistencia armada no les llevaba a nada”. De esta manera, siguen buscando "métodos más convenientes y que den mejores resultados”.

\section{La Noviolencia es un concepto occidental que difiere de las con- cepciones indígenas.}

Esta opinión se ve en dos afirmaciones, uno de los académicos que afirma que "el concepto de Noviolencia no se encuentra en las comunidades, porque es un concepto de afuera, occidental”, y para de uno de sus líderes, "el análisis de Gandhi es desde occidente y por la búsqueda de condiciones sociales en general; la lucha de los Nasa en cambio es por la búsqueda del dialogo con otra lógica que se quiere imponer”.

\section{Análisis de los resultados}

En el primer resultado, se puede ver que la Noviolencia se asocia a la armonía, el bienestar y el concepto de Kweet Fxindxi, existiendo una relación con la paz y con, prácticamente, todas las dinámicas de su comunidad. Estos principios pueden ser considerados como el constructo ideológico de las comunidades, en la medida que están presentes en casi todos los ámbitos de la vida indígena.

Si analizamos los resultados obtenidos para la categoría de Noviolencia, podemos encontrar muchas afinidades entre la definición Nasa de Noviolencia, y la forma en que ésta es entendida por el gandhismo aunque dentro de las comunidades no exista una noción elaborada, desarrollada o definida del concepto-. En este primer resultado se aprecia cómo la Noviolencia queda asociada a una de sus bases cosmológicas, el Kweet Fxindxi o principio de armonía y equilibrio. Es claro, que es ejemplo de hasta qué punto, dentro de las comunidades indígenas, existe una ideolo- 
gía de qué es lo que quieren las comunidades -fines- y de cómo quieren conseguirlo puesto que estas hablan de armonización y no de violencia. Estas ideas guardarían una relación directa con los conceptos de Ahimsa, Sarvodaya, Swadeshi y Swaraj.

El segundo resultado, es aún más cercano a la idea de Noviolencia gandhiana, puesto que si se parte del principio de Ahimsa, que considera que resulta mucho más productiva y cimentada a la hora de construcción del tejido social, las relaciones y las interacciones comunitarias. Para que esto se pueda construir junto al "otro", es necesario y sólo es posible mediante la renuncia de las armas y mediante la máxima de que entre "hermanos" siempre se encontrarán soluciones. El poder social que se construye desde la Noviolencia es la idea consciente y voluntaria de que se pueden dirimir las contradicciones y los conflictos sin la necesidad de recurrir a la violencia, lo que ejemplifica claramente la gran similitud entre ambas concepciones de la Noviolencia -la Nasa y la gandhiana-.

En el tercer resultado, se puede ver que progresivamente, la Noviolencia es asimilada a un sueño o a un fin dentro de las comunidades. Esta asimilación se debe a la "compatibilidad, ductilidad y adaptabilidad a muchas exigencias políticas y sociales” (López 2013: 230) que viene del principio de construir poder social. Por esta razón, las comunidades la ven como una actitud, como un tipo de conducta a seguir, como un hábito y una cotidianidad a alcanzar.

El cuarto resultado, presenta otros elementos centrales en relación a la Noviolencia, como son el situarse como actor dentro de la sociedad, el cual debe hacer un ejercicio de poder; o el saber que el poder de los gobiernos está sustentado en la obediencia voluntaria de los gobernados, lo que, en el caso Nasa, ha sido inteligentemente manteniendo bajo la forma de "se manda obedeciendo", quedando en este caso el liderazgo y la autoridad supeditadas a la comunidad y al revés. En este sentido, "mandar obedeciendo" es la construcción del poder social, del poder desde abajo; es el ejercicio de la Noviolencia, que se hace tanto desde el convencimiento individual y la lucha de cada uno de los miembros, como desde el consenso colectivo, en el que la búsqueda de soluciones negociadas, sin la vía de las armas y para la defensa de la vida, es un mandato "sagrado" dentro de la comunidad.

En este resultado también se evidencia que la idea Nasa de Noviolencia no es de pasividad, de tolerancia exacerbada, de resignación, sino que se trata de que, si se construye en sociedad y el poder emana desde el papel que cada uno cumple y ejerce en la comunidad, es necesario que existan unas reglas de convivencia o planes consensuados que determinen los límites de lo que se tolera y lo que no, así como el papel que cada miembro debe cumplir dentro de dicha población. Desde la "teoría de juegos" se habla de la existencia de reglas formales o "institucionalizadas" y de reglas informales, entendidas como "implícitas" dentro de un contexto. Estas reglas informales, desde la teoría gandhiana, no son otra cosa que la 
implementación de la “moral en la política”; es decir, al igual que individualmente tiene que haber unos parámetros para la convivencia y la interacción, también tiene que haberlos a nivel colectivo y de comunidad. Así, lo "publico" y lo "privado" no pueden distanciarse. Para Gandhi estas reglas o principios “morales" sólo se pueden construir desde una "verdad epistemológica”: el consenso entre los miembros de la comunidad y la consecución de unos programas constructivos, lo que para el caso Nasa se concreta en los planes de vida.

El quinto resultado hace referencia a la dimensión pragmática de la Noviolencia, aunque no se queda en la parte meramente "instrumental” o de “defensa”, asociándola a una forma de vida bastante conveniente para los Nasa, pues la Noviolencia facilita el diálogo y el entendimiento, permitiendo además un cambio de mentalidad. De ahí la importancia del término cuando las comunidades indígenas hablan de "una resistencia desde el pensamiento", pues en realidad se trata de una lucha contra el colonialismo. Para reafirmar esta idea, según López (2008: 233): “el ejercicio de la Noviolencia implica intervenir de manera activa e imaginativa en los conflictos, envolverse y mezclarse con la violencia para contrarrestarla, y presentar alternativas pacíficas para resolver dificultades y controversias”.

El sexto resultado, por su parte, es un claro ejemplo del notable desconocimiento, de ciertos tópicos, y tal vez la banalización que demuestran ciertas escuelas sociales y políticas frente al concepto de Noviolencia. En primera instancia, el pensar que los Nasa no conciben el concepto de Noviolencia porque no lo han llevado a un nivel “académico" o "teórico" es ignorar el carácter universal y adaptativo de la Noviolencia, y por ende, desconocerla. En este sentido, dieciocho de las veintidós personas entrevistadas han contestado a la pregunta “¿qué es la Noviolencia?”, dándose en algunos casos elaboradas y concretas definiciones del concepto, y tan sólo dos opiniones que afirmen que se trata de algo occidental.

Además de estos resultados es importante y cabe destacar dos afirmaciones, que aunque en la tesis doctoral se abordaron en el apartado procesos de resistencia comunitaria en la resistencia noviolenta, en este artículo es importante traerlas a colación. Estas dos afirmaciones son una definición de Noviolencia de uno de los miembros, y la otra, es una de las opiniones frente a la concepción de que "todos somos hermanos".

En este orden de ideas la definición de Noviolencia de los Nasa que es importante destacar en este artículo es:

Pues la Noviolencia es como tener la capacidad de poder controlar las conductas, los actos a la fuerza, pues todo se debe hacer no a la fuerza, se debe hacer con dialogo, con el uso de la razón, más que imponer las cosas a la fuerza, sin razón alguna, pues con unos principios: el principio de la reciprocidad, el principio de la redistribución, el principio de la vida, de la vida digna, entonces pues consideramos que hacer ese ejercicio sin necesidad de eliminar al otro, de eliminar 
al otro de agredir al otro y de imponer, una propuesta, una cultura, un pensamiento a la fuerza, sino que pues como hablamos de la Noviolencia, se debe es compartir, se debe solidarizar, bajo los principios del reconocimiento y del respeto, reconocimiento del otro y del respeto, eso entendiendo como la Noviolencia.

Esta definición de Noviolencia habla por sí sola y evidencia las relaciones y las similitudes que existen entre lo que definen las comunidades Nasa y los conceptos desarrollados por Gandhi y posteriormente la teoría de la Noviolencia. En este sentido sin existir una conexión clara entre estas dos experiencias, ambas tienen elementos que partiendo de su especificidad, han elaborado y desarrollado conclusiones muy similares y congruentes.

El segundo aspecto a resaltar es una de las relaciones que comenta uno de los miembros de la comunidad y se evidencia en la siguiente cita:

La Noviolencia, aunque puede que los mayores no sepan quién es Gandhi, dentro de la comunidad hay una actitud humana de afrontar los conflictos (...) es tratar al otro también como a un hermano, porque desde allí siempre se encuentran muchas soluciones, por eso Gandhi decía “todos somos hermanos” y quizá ese principio no esta tan arraigado en otros movimientos como en el Nasa.

La idea de que "todos somos hermanos" es fundamental para la Noviolencia y su entendimiento, el hecho que las comunidades indígenas desde otros caminos, lo asimilen de la misma manera, lo que acerca a estas dos experiencias de manera más clara y directa.

\section{Conclusiones}

Esta primera conclusión,pretende dejar de manera másclara y explícita, que el concepto de Noviolencia gracias a su versatilidad, a la universalidad de sus valores, $\mathrm{y}$ a la gran cantidad de acciones se puede llevar a cabo por cualquier grupo o individuo, puesante todo, busca la humanización de las relaciones sociales, la incorporación de valores éticos y morales a la política y esencialmente brinda herramientas para poder equiparar la Noviolencia a una lucha militar, o armada sin precisamente tener que llegar al uso de dichas armas o de la violencia.

La Noviolencia al tratarse del recurso que tiene todo individuo antes de poder acceder a las armas, el tratarse de un poder que se encuentra inmerso en cada persona, al ser el poder intrínseco que tiene cualquier comunidad, se manifiestay es susceptibles de lectura y de comparación en diferentes contextos y lugares del mundo. Aunque existan sustratos y valores culturales y cosmológicos diferentes, hay condiciones de resistencia, de rebeldía, de inconformidad, que se dan cuenta de lo nociva de la violencia y lo simplista que puede ser la pasividad, llevándolos a conclusiones similares que se sintetizan en gran medida en el concepto y los supuestos 
de la Noviolencia. Esta teoría tiene la convicción de que es más revolucionario y más sedimentado el cambio y la transformación de los conflictos sin el recurso de las armas, que con su uso de estas.

Como segunda conclusión, se quiere reafirmar que, existe una noviolencia pragmática en la que no se tienen en cuenta los valores o la ideología; y aunque ésta noviolencia pragmática en cierto sentido permite el acercamiento y una practica inicial de la acción política noviolenta, esta claro como bien afirman autores como Pontara o el mismo Gandhi, que es necesaria la congruencia y el cuidado tanto de los medios, como de los fines. No son cosas que se puedan pensar por separado, la noviolencia no es compatiblecon cualquier ideología. La historia nos ha venido mostrandoque ni todo fin justifica el uso de unos medios, ni que los medios son absoluto garante de que los fines no se puedan llegar a pervertir.

No se puede pensar únicamente en la eficacia y eficiencia a la hora de obtener resultados, sino que se tiene que tener claros cuales son los resultados que se están esperando (los fines).Experiencias como el Nazismo en su primera fase, dieron cuenta de ello ysirven como ejemplo, en la medida que usaron muchos de los métodos de persuasión y protesta que ha tratado Sharp como métodos de acción noviolenta.La eficacia de los medios no armados fue innegable y sirvió como estrategia para llegar a otros medios comolas armas, la coerción y la violencia legal.

El hecho que las comunidades indígenas piensen en la armonía y el bienestar de sus comunidades desde todo lo que engloba la idea de Kweet Fxindxi, hacen que los medios y los fines tengan gran compatibilidad, hecho que facilita el ejercicio de la teoría noviolenta en una práctica propia y específica Nasa. De esta forma aunque de manera inicial el uso de la noviolencia pragmática permitió el acercamiento de las comunidades con la teoría, han sido los fines, los que han provocado la permanencia de estas prácticas en sus formas de vida.

La tercera conclusión, es que al igual que existen grandes similitudes entre el concepto de Noviolencia de las comunidades indígenas Nasa y el gandhismo, también existen muchas otros aspectos y ámbitos que son susceptibles de comparación, y pueden ser entendidos desde una lectura de la Noviolencia, de corte académico. Aspectos como la cosmovisión, en lo relacionado a la armonía o el bienestar, los conceptos de verdad, de paz, de autonomía, de autosuficiencia, de resistencia, entre otros, se pueden analizar. Los aspectos sociales, la historia, los aspectos políticos, los procesos de resistencia, la Guardia Indígena, entre otros, son aspectos que se deben tener en cuenta para entender las relaciones existentes entre el gandhismo y la resistencia Nasa. Por esta razón, en la investigación de tesis doctoral, del cual hace parte este artículo, se tuvieron en cuenta todos estos aspectos queson importantes de abordar si se quiere profundizar en el estudio de diversas comunidades, desde este enfoque y perspectivacomo la es la de laNoviolencia. 
Como cuarta y última conclusión, es pertinente no olvidar que se tratan de noviolencias específicas, en donde la historia, los contextos, los valores, las relaciones comunitarias y características propias, son determinantes, y marcan el camino y los senderos para llegar a conclusiones similares, que aunque son susceptibles de comparación, siempre serán experiencias únicas e irrepetibles, que tienen mucho que aportarse las unas a las otras, y sobre todo, que abren y muestran un camino para el estudio de diversas comunidades indígenas o no indígenas en el resto del mundo, las cuales ayuda a continuar con la escritura de esa gran olvidada como es la larga historia de la Noviolencia. 


\section{Notas}

${ }^{1}$ Este artículo hace parte de la Investigación de tesis Doctoral titulada "Caminando hacia la Satyagraha. Comunidad, lucha y KweetFxindxi en los Nasa (1972-2015)” que ha sido realizada en el Instituto de la Paz y los Conflictos de la Universidad de Granada, España, siendo finalizada en enero de 2016.

${ }^{2}$ Es la comunidad indígena más representativa del departamento del Cauca, Colombia. Están asentados en el territorio conocido como Tierradentro ubicado en el sur-occidente de Colombia. Se encuentra en la vertiente oriental de la cordillera central de los Andes. Son conocidos por la tradición historiográfica española como gente Páez, pero a partir del nombre de su lengua Nasa Yuwe, esos se auto-reconocen y reafirman como indígenas Nasa. (PACHON: 1996)

${ }^{3}$ Se autodefinen como plataformas de trabajo social y comunitario en el que a través del desarrollo de procesos de organización han hecho respetar sus derechos como pueblos autónomos y originarios del territorio colombiano. En este sentido son la unión de diferentes procesos comunales que se han gestionado desde las mismas comunidades indígenas con el fin de generar estas instituciones más amplias y mejor organizadas desde las que pueden reclamar más visiblemente sus derechos. (En: www.Nasaacin.org)

${ }^{4}$ A la hora de consultar su página web y buscar las referencias sobre el Proyecto Nasa, y los resguardos de Toribio, San Francisco y Tacueyó (en: www.Nasaacin.net)

${ }^{5}$ La doctrina pacifista ya existía con mucha anterioridad, sin embargo es en este momento de gran algidez y sobre todo con altos contenidos de violencia cuando una iniciativa como la de Godwin toma importancia. Es uno de los precursores del entendimiento de la lucha de masas con la importancia de los contenidos pacíficos en la era contemporánea. Si se quiere ver más información sobre formas de pacifismo se puede ver artículo de (López 2006).

${ }^{6}$ Del mismo modo que en este momento se habla de una resistencia pasiva porque no lleva inmerso un contenido violento, siguiendo con los preceptos del Marxismo y, en algunos casos, del Anarquismo, muchas de las expresiones que fueron de índole pacifica o pacifista fueron desdeñadas y ridiculizadas por estas corrientes predominantes a lo largo del siglo XIX. Otro buen ejemplo de ello se puede ver en el concepto de socialismo, en el que Marx, para distinguirse del énfasis propuesto por Pierre Leroux, quien acuñó por primera vez el término de socialismo y quien abogaba por una lucha no armada, llamó a su socialismo “científico”, legitimando así el uso de la violencia, y al socialismo de Pierre Leroux y de otros muchos pensadores de la época, como "socialismos utópicos”, haciendo referencia a la imposibilidad de su realización sin medios armados. (Castañar 2013:59-60)

${ }^{7}$ De esta manera se puede ver que el concepto puede ser percibido, en primera instancia, de manera negativa, que parte del no matar, no causar daño o sufrimiento (ahimsa) y una perspectiva positiva, que parte del generar mayor cantidad de bienestar.

${ }^{8}$ López le da el término de Genérico, el cual expresa la misma idea y hace referencia al uso compatible con cualquier ideología, para efectos prácticos se usaran indistintamente los dos términos. 
${ }^{9}$ López siguiendo a Pontara, lo llama Específico en relación a su carácter.

${ }^{10}$ Una obra que ha recogido diversas cartas, artículos, entrevistas y otros escritos, que está compuesto por más de noventa volúmenes es la que reúne The collected Works of Mahatma Gandhi, publicados en ciudad de Delhi, por el gobierno de la India entre los 1958 y 1984, en (Pontara 2004: 493)

${ }^{11}$ Los paréntesis cuadrados son míos

${ }^{12}$ Esta clasificación es expuesta por López por primera vez en: (2001: 236-242), sin embargo a lo largo de diversos estudios, esta tipología, la va completando y ampliando, de tal manera que uno de los lugares donde mejor podemos encontrar el avance de su tipología es en (López2013)

${ }^{13}$ Para este autor, está claro, que aunque en muchos de estos ejemplos no se da una noviolencia específica, en la que se busca un programa creativo con el adversario, sino que en muchas ocasiones se trata de una noviolencia pragmática, todos estos ejemplos, son importantes en la medida en que han presentado cambios significativos en la humanización del conflicto. (López 2013: 40)

${ }^{14}$ Algunos de los ejemplos que el autor menciona en el articulo son: La independencia de las Trece colonias, Cuba (1810-1903), Argelia (1830-1950), Egipto (1805-1922), Ghana (1890-1950), Mozambique (1920-1970), Sudáfrica (1899-1919), India (19001947), Polonia (1860-1900), Hungría (1850-1860), Irlanda (1919-1921), Palestina (1920-2012), entre otros. Para ver mejor estos casos se puede ver, (Ibíd.: 37)

${ }^{15}$ Los ejemplos que presenta Mario López son: La huelga general en Rusia en 1905, la resistencia noviolenta en Holanda (1940s), Resistencia los maestros en Noruega (1940s), La resistencia de Dinamarca, La oposición ha Hitler de la organización Rosa Blanca, la resistencia civil de las mujeres en Italia (1943-1945) las campañas contra la dictadura en Salvador (1944), el apartheid en Sudáfrica, la primavera de Praga en Checoslovaquia (1968), el colapso de los regímenes soviéticos y la Caída del muro de Berlín (1989) entre otros. (Ibíd:38) 
Polis, Revista Latinoamericana, Volumen 15, $N^{\circ}$ 43, 2016

\section{Bibliografía}

Ameglio, Pietro (2002), Gandhi y la desobediencia civil. México hoy, Plaza y Valdés, Ciudad deMéxico

Bobbio, Norberto(1992), El problema de la guerra y las vías de la paz, Gedisa, Barcelona.

Castañar, Jesús (2013), Teoría e Historia de la revolución Noviolenta, Virus, Barcelona.

Clausewitz, Karl (2010), De la guerra, Biblioteca Virtual Universal [http:/ /www.biblioteca.org.ar/libros/153741.pdf] Cardo, Argentina

Congreso de los Pueblos (2014), Poder popular para la vida digna, Impresos y Suministros de Oriente, Saravena.

Galeano, Myriam (2006), Resistencia Indígena en el Cauca. Labrando otro Mundo. Feriva, Popayán.

Galtung, Johan (2003), Paz por medios pacíficos. Paz y conflicto, desarrollo y civilización, Red Guernika, Guernica.

Gandhi, Mohandas (1998), Todos los hombres son hermanos, Librería Dersa, Madrid.

Ídem (2002), "El programa constructivo de la India. Su significado y su uso” en Ameglio, Pietro, Gandhi y la desobediencia civil. México hoy. Plaza y Valdés, Ciudad de México.

Ídem (2004), Escritos esenciales, Sal Terrae, Santander.

Hernández, Esperanza (2004), Resistencia Civil Artesana de Paz. Experiencias indígenas, afro descendientes y campesinas, Universidad Javeriana, Bogotá.

Ídem (2006), “La Resistencia Civil de los indígenas del Cauca” en: Papel Político, Vol. 11 No 1, http://www.javeriana.edu.co/politicas/publicaciones/documents/6LARESISTENCIA, Universidad Javeriana, Bogotá.

Ídem (2012), Intervenir antes que anochezca. Mediaciones, intermediaciones y diplomacias noviolentas de base social en el conflicto armado colombiano, Universidad Autónoma de Bucaramanga, Bucaramanga.

Herranz, Rafael (1992), Henry D. Thoreau: Resistencia y Desobediencia Civil. CEU Luis Vives, Madrid.

Laurent, Virggine (2005), Pueblos Indígenas y Espacios Políticos y Movilización Electoral. 1990 - 1998, ICAH, Bogotá. 
López, Mario (2001), “La Noviolencia como Alternativa Política”, en: Muñoz, Francisco, La Paz Imperfecta, Universidad de Granada, Granada.

Ídem (2004), “Principios y Argumentos de la Noviolencia” en: Molina, Beatriz y Muñoz Francisco Manual de paz y conflictos. Universidad de Granada, Granada.

Ídem (2006), Política sin violencia, Universidad Minuto de Dios, Bogotá.

Ídem (2013), “Política sin matar. Los métodos de la acción noviolenta.” Vectores de investigación $\mathrm{N}^{\circ}$ 7, Universidad Complutense, Madrid.

López, Mario, Martínez Carlos y Useche Óscar (2008), Ciudadanos en son de paz. Propuestas de acción noviolenta para Colombia, Universidad Minuto de Dios, Bogotá.

Losada, Rodrigo y Casas Andrés (2008), Enfoque para el Análisis Político. Historia, epistemología y perspectivas de la ciencia política. Universidad Javeriana, Bogotá.

Maquiavelo, Nicolás, El príncipe, el aleph.com, http:/www.educ.ar/sitios/ educar/recursos/ver?id=91778

Martínez, Daniel (2006), Experiencias de paz y noviolencia: Resistencia civil de los indígenas del Cauca, el proyecto Nasa, Trabajo de Grado en de Ciencias Políticasy Relaciones Internacionales, Universidad Javeriana, Bogotá.

Ídem (2009), La Resistencia Indígena Comunitaria de los Pueblos Nasa: Una Experiencia De Noviolencia Positiva. Trabajo de Magister en Paz, Conflictos y Democracia, Universidad de Granada. Granada.

Ídem (2016), Caminando hacia la Satyagraha. Comunidad, lucha y Kweet Fxindxi en los Nasa (1971-2015) Tesis doctoral en Paz Conflictos y Democracia, Universidad de Granada, Granada.

Pachón, Ximena (1996), “Los NASA o la gente Páez”, en: Instituto Colombiano De Cultura Hispanoamericana, Geografía Humana de Colombia, Región Andina Central, Tomo IV volumen II, Colección Quinto Centenario, Bogotá.

Pontara, Giuliano (1982), “Noviolencia” en Bobbio, N., N Matteuccci y G. Pasquino, (Eds.) Diccionario de Política, Siglo XXI, Madrid.

Ídem (2004) “Gandhismo” en: López Mario, Enciclopedia de paz y conflictos, Tomo I., Universidad de Granada, Granada.

Randle, Michael (1998), Resistencia Civil. La ciudadanía ante las arbitrariedades de los gobiernos, Paidós, Barcelona. 
Polis, Revista Latinoamericana, Volumen 15, $N^{\circ}$ 43, 2016

Rappaport, Joanne (2000), La política de la memoria: interpretación indígena de la historia de los Andes colombianos, Universidad del Cauca, Popayán.

Scott, James (2000), “Los dominados y el arte de la resistencia”, Ediciones Era, Ciudad de México.

Semelin, Jacques (1993), Unarmed against Hitler: Civilian resistance in Europe, 1939-1943, Praeger Publisher, New York.

Ídem (2001), La no-violencia explicada a mis hijas, Plaza y Janés. Barcelona.

Sharp, Gene (1973), “The Politics of nonviolent action”. 3 vols, Porter Sargent, Boston.

Vitale, Ermanno (2012), Defenderse del Poder. Por una resistencia constitucional. Trotta, Madrid.

Useche, Óscar (2014), Micropolítica de las resistencias sociales noviolentas. El acontecimiento de las resistencias como apertura de nuevos territorios existenciales Tesis doctoral en Paz Conflictos y Democracia, Universidad de Granada, Granada.

Recibido: 30.01.2016

Aceptado: 05.04.2016 